\title{
Lorca y Colombine: mujeres en Campos de Níjar
}

\author{
Mar Correa García | periodista \\ URL de la contribución <www.iaph.es/revistaph/index.php/revistaph/article/view/4084>
}

\section{RESUMEN}

Las leyendas y romances forman parte de la historia de los Campos de Níjar, forjada entre cerros pelados, desiertos y cortijos abatidos por el viento; cuna de mujeres luchadoras e invencibles que se debatían en los albores del siglo $\mathrm{XX}$ entre su propia libertad y un patriarcado implacable que ahogaba sus sueños. El espejo en el que se reflejan las tradiciones y costumbres de la Almería campesina, hasta transformarlas en mito, son las grandes obras de la literatura española Bodas de sangre, de Federico García Lorca, y Puñal de claveles, de Carmen de Burgos, Colombine, que narran las ansias de huir de ese forzoso silencio y docilidad que les eran impuestos a estas mujeres invisibles desde antes de nacer. Algunas pagaron su osadía con el ostracismo, otras incluso con su vida, las más vieron truncar sus ilusiones entre soledades de matrimonios pactados y mal avenidos. La brillantez literaria de Lorca y De Burgos encubre el origen del suceso real en el que los autores se inspiraron: la trágica vida de Francisca Cañadas, la hija del aparcero del cortijo del Fraile, que una madrugada de julio de 1928 fantaseó con el amor y la libertad hasta que la venganza y los ritos atávicos desgarraron sus jóvenes inquietudes. Este artículo va en memoria de Paca Cañadas y de esas miles de resueltas almerienses, porque forman parte de la memoria de los Campos de Níjar, porque lucharon con denuedo por romper con ritos irracionales que las anulaban por ser mujeres, porque hicieron historia sin saberlo y escribieron los primeros capítulos de la liberación femenina.

\section{Palabras clave}

Almería | Burgos, Carmen De "Colombine" | Campos de Níjar | García Lorca, Federico | Mujeres | 


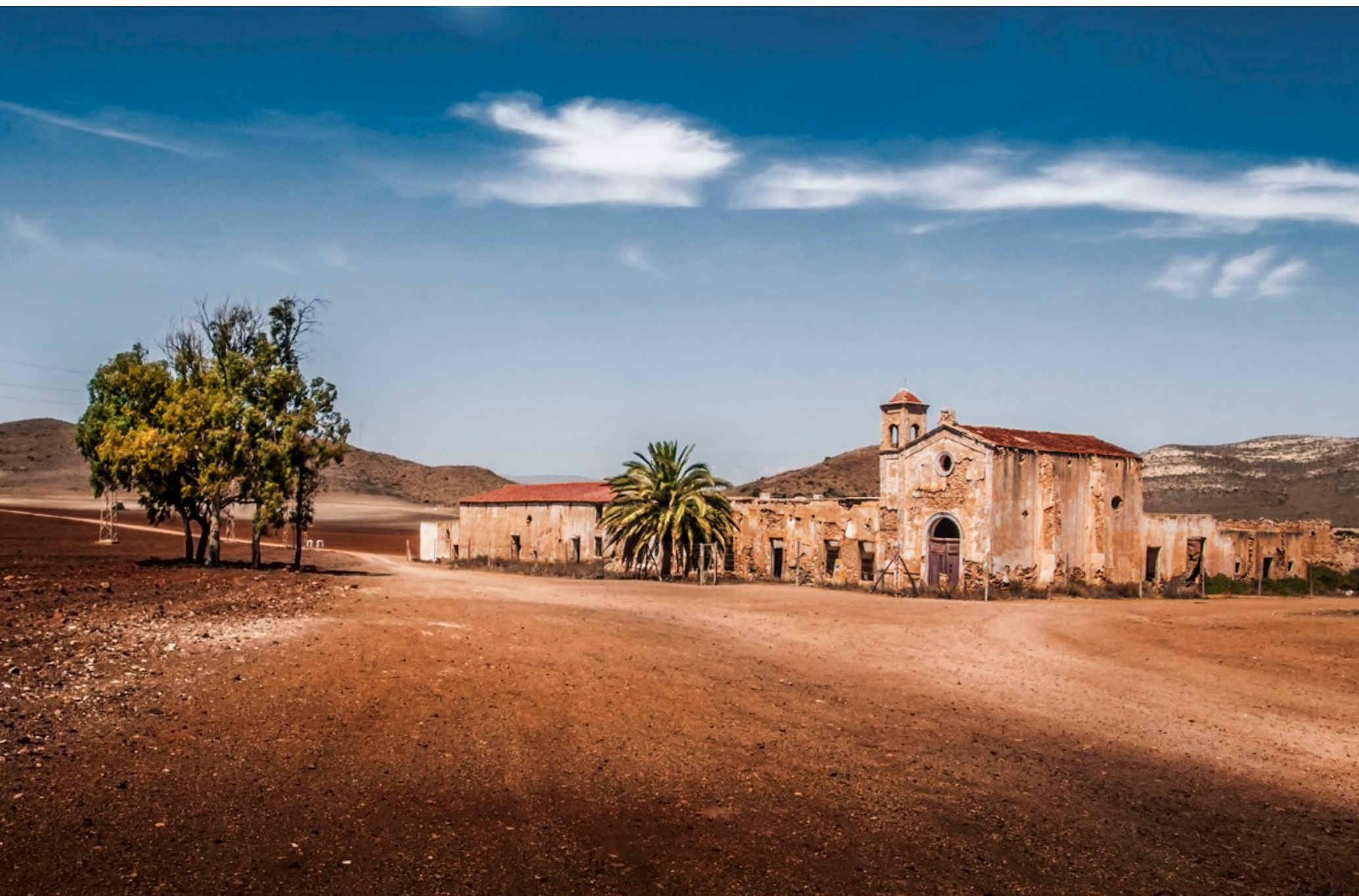

El cortijo del Fraile, el 24 de septiembre de 2012 | foto Jose Terol 
"Se consumió aquí"... "como nos consumimos todas"
Bodas de sangre

Cerros desmochados, deshabitados y hostiles, ocres partidos por el azul intenso del mar, oasis salpicados de pitas, palmeras y atochas; cortijos solitarios y silenciosos espurreados por un desierto curtido por el viento. El paisaje agreste de los Campos de Níjar alberga el alma rural almeriense que encuentra refugio en sus polvorientos caminos para proteger sus leyendas y primitivas tradiciones del mundo exterior. La magia telúrica que emanan sus piedras, trochas, bancales y hasta el agua que alberga sus centenarios aljibes, han servido de inspiración a romances, coplillas, versos, cuentos, crónicas, películas y novelas, que viajan en el tiempo como un retrato costumbrista y antropológico de vidas tan yermas como la tierra pero plagadas de luchas entre la pasión y el convencionalismo, entre la libertad y la losa de un patriarcado feroz que impelía a la mujer a vivir reprimida y servil bajo el yugo de un hombre-amo y señor.

Este paisaje, estos campesinos y estos ritos se confabularon para iluminar una de las obras cumbre del teatro español del siglo XX: Bodas de sangre (Federico García Lorca, 1933); y una novela realista cargada de descripciones costumbristas que alentaban a la mujer a huir de sus negros designios: Puñal de claveles (Carmen de Burgos, Colombine, 1931). Ambas obras son la interpretación narrativa de un suceso real ocurrido en julio de 1928

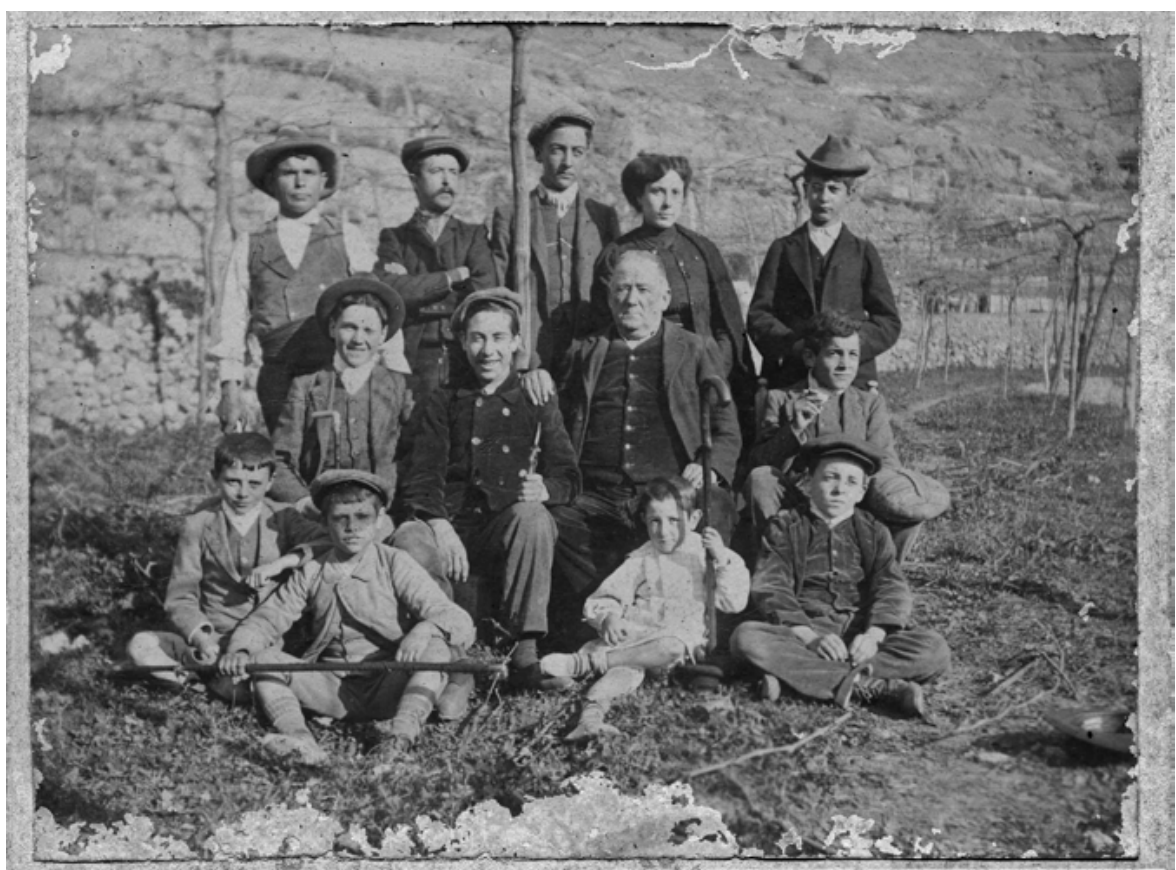


conocido como el "crimen de Níjar", del que se hizo eco la prensa local y nacional: la joven hija del aparcero del cortijo del Fraile, Francisca Cañadas, huyó con su primo Paco Montes unas horas antes de su boda con Casimiro Pérez, hermano de su cuñado. Su propia hermana, Carmen Cañadas, y su marido, Juan Pérez, vejados por la humillación y el deshonor, persiguieron a la pareja hasta dar muerte al novio y dejar malherida a la incauta novia. Al margen de esa honra, que había que limpiar con sangre para reparar el daño, la huida de Paca Cañadas destrozó además las previsiones de su hermana Carmen y su marido Juan respecto a la generosa dote con que contaba la novia.

"No era raro en la comarca que un antiguo novio robase a la desposada en su boda, en el momento supremo de ir a perderla, y de que una boda preparada con alegría terminase con sangre. Encajaba dentro de las costumbres de aquel pueblo de clima meridional, de raza moruna y de temperamento sin desbastar" (DE BURGOS, 2017: 154).

Pretender huir del espacio doméstico al que la mujer estaba indefectiblemente relegada, con un matrimonio acordado y un marido apenas conocido, se pagaba muy caro en los albores del siglo XX. La infamia y el escándalo perseguiría de por vida a Francisca Cañadas, que murió soltera y sola, recluida hasta su muerte, en su cortijo de El Hualix.

El propósito de las mujeres en aquellos no tan revolucionarios años 20 era ser hija recatada y mansa, esposa sumisa y madre perfecta. "No habla nunca; suave como la lana, borda toda clase de bordados y puede cortar una maroma con los dientes". Así describía a su hija el padre de la novia en Bodas de sangre: una mujer silenciosa, dócil, hacendosa y sana (GARCÍA LORCA, 1944: 38).

El matrimonio era el único objetivo en unas vidas dependientes del padre primero y del esposo después; un enlace con una función básicamente utilitaria, supeditado a la estructura económica y social de ambas familias y cuyo designio no era más que la función de procrear: en el campo siempre eran necesarios brazos para trabajar. "Así es que cuando su padre le habló de que la había pedido en matrimonio Antonio el Peneque, que gracias a su suerte en el contrabando había llegado a ser dueño del cortijo de los Tollos, ella lo aceptó sin alegría y sin repugnancia" (DE BURGOS, 2017: 114).

Si la familia no había elegido aún al pretendiente más adecuado, no había más posibilidad de conocer varón que los bailes que se celebraban en los cortijos mayores, las verbenas en los pueblos o las misas de domingo. Las muchachas iban siempre acompañadas por sus madres o las vecinas, que ni a sol ni a sombra dejaban solas. Los postulantes aprovechaban el baile para rondar a las jóvenes que se dejaban deslumbrar. "Un hombre con su caba- 
Ilo sabe mucho y puede mucho para poder estrujar a una muchacha metida en un desierto" (GARCÍA LORCA, 1944: 56). A partir de ahí, y siempre que el capital del aspirante fuera de merecer, el joven se atrevía a pedir a los padres de la muchacha permiso para enamorarla. El riesgo de quedar soltera era tan deshonroso y denigrante, que las jóvenes aceptaban con complacencia un noviazgo exento de amor y de pasión, confidencias e intimidad. De hecho era frecuente que la novia quedara a solas por primera vez con su esposo en la misma noche de bodas.

El estricto protocolo rural en los Campos de Níjar en los albores del siglo XX establecía que las mujeres vistieran de negro el día de su boda, costumbre apocalíptica habida cuenta que muchas de las jóvenes asistían a su propio entierro el día que contraían nupcias.

En ocasiones, como en el caso de las tres novias que nos ocupan -la que vivía en el cortijo del Fraile, la de Lorca y la Pura de Colombine-, la joven se debate en un conflicto interno entre su deber como hija y su realización individual como mujer; entre sus deseos de amar y conocer un mundo más allá del desierto nijareño, y su necesidad de acatar las implacables formalidades que en la mayoría de los casos acababan imponiéndose.

Pero no siempre habría sumisión. Hubo mujeres decididas e intrépidas que no vieron otra salida a un destino fatal más que escapar de unas obligaciones que se veían forzadas a asumir desde muy temprana edad (la mayoría de las campesinas almerienses contraían nupcias entre los 16 y los 20 años). Francisca Cañadas instó a su primo -que jamás le confesó pasión alguna- a huir; la novia de Lorca escapó con Leonardo, su antiguo amor -hombre casado además-; la Pura de Colombine se dejó embelesar por Joseíyo, amigo íntimo del novio. Las tres sueñan con fugarse de ese cerco opresor al que estaban confinadas desde antes de nacer.

Es posible que muchas más soñaran con esa evasión desesperada. "¿Tú sabes lo que es casarse, criatura?", avisa la madre del novio a la desposada en Bodas de sangre: "Un hombre, unos hijos y una pared con dos varas de ancho para todo lo demás" (GARCÍA LORCA, 1944: 40).

Esta es la advertencia de mujeres que conocen sobradamente la prisión que representa para ellas un casamiento, mujeres que ven marchitarse su belleza y su juventud entre solitarios muros y piedras: "Tú, a tu casa/ Valiente y sola en tu casa/ A envejecer y a llorar/ Pero la puerta cerrada" (GARCÍA LORCA, 1944: 113).

Ya desde el momento en que se publicaban las amonestaciones en la iglesia, un mes antes de la boda, las prometidas ya no debían de ser vistas en público. "Vamos, que ya está ya presa" (DE BURGOS, 2017: 119). Y casa- 
das, no se les permitía llevar la cabeza descubierta, arreglarse o acudir a fiestas si no era acompañando a sus hijas. Si ya pertenecían a un hombre, ¿para qué exhibirse?, ¿para qué salir?

Pese a ser conocedoras de unas costumbres irracionales, son las madres en las obras de García Lorca y de Carmen de Burgos el baluarte del autoritarismo y la intransigencia social. Las que mantienen y defienden los patrones patriarcales, guardianas de la costumbre y la moral, las que vigilan con bravura la virginidad de sus hijas, cara alhaja que se preserva para el varón elegido.

Madres que educaban a sus hijas en la sumisión, que perpetúan su papel subsidiario y trivial y que aceptan la infidelidad de los varones, incluso se jactan de la naturaleza animal de sus hombres, herencia de la poligamia árabe. "Tu abuelo dejó un hijo en cada esquina. Eso me gusta. Los hombres, hombres; el trigo, trigo" (GARCÍA LORCA, 1944: 12).

Así pues, no es de extrañar que esa huida alocada -teñida de sangre en ocasiones- se convirtiera en el sueño de esas jóvenes sin más formación que la cocina, los bordados, la costura y los trabajos de campo (la tasa de analfabetismo entre mujeres a principios del siglo XX en el campo andaluz rondaba el $80 \%)$.

“¿De qué servía ni siquiera ser hermosa en aquel desierto?”, se preguntaba la Pura de Puñal de claveles (DE BURGOS, 2017: 110); un desierto de soledad y servidumbre del que unas pocas mujeres escaparon para escribir una línea más en la larga historia de la igualdad y la liberación femenina. Mujeres luchadoras, valerosas e invencibles, que escribieron la historia de Almería, que esculpen su leyenda en los cerros de los Campos de Níjar. 


\section{BIBLIOGRAFÍA}

- BIEDER, M. E. (2005) Literatura y feminismo en España. Barcelona: Icaria Editorial, 2005

- CEBA, J. J. (2017) Prólogo y epílogo de "Puñal de claveles". En DE BURGOS, C. Puñal de claveles. Almería: Editorial Letra Impar, 2017

- DE BURgos, C. (2000) El artículo 438. En DE ACUÑA Y VILLANUEVA, R.; CORREA RAMÓN, A. Cuentos de mujeres: doce relatos de escritoras finiseculares. Madrid: Clan Editorial, 2000 (Colección Cuentos de Autores Españoles)

- DE BuRgos, C. (2017) Puñal de claveles. Almería: Editorial Letra Impar, 2017

- DE BURgoS, C. (2016) La malcasada. Sevilla: Editorial Renacimiento, 2016

- GARCÍA LORCA, F. (1944) Bodas de sangre. Buenos Aires: Editorial Losada, 1944

- GARCÍA LORCA, F. (1976) Yerma. Madrid: Ediciones Cátedra, 1976

- SÁNCHEZ SEVILLA, F. (2017) Estudio de la novela corta Puñal de claveles. En DE BURGOS, C. Puñal de claveles. Almería: Editorial Letra Impar, 2017 